\title{
La conceptualización antropológica del indio en el Cusco (1942-1973)
} Esquema para entender la antropología en el Perú desde la diversidad

Recibido: 05/06/2019

Aprobado: 10/09/2019
CÉSAR AGUILAR

Universidad Nacional Mayor de San Marcos

cesar.aguilar.unmsm@gmail.com

\section{RESUMEN}

El objetivo de este artículo es explicar las causas, fuentes y procesos de conceptualización antropológica sobre el indio —entendido como objeto de estudio - que se desarrollaron en Cusco, desde 1942, año de fundación institucional de la disciplina, hasta 1973, año de su primera gran crisis. En ese sentido, planteo que dichos procesos de conceptualización estuvieron condicionados por la manera como se configuraron las condiciones sociales y políticas de los antropólogos, en relación a la teoría antropológica que se leía por esos años y la situación institucional de la disciplina. Todo esto, frente a determinados contextos ideológicos — como los indigenismos-y sociopolíticos — como las revueltas sociales.

Palabras clave: Antropología, objeto de estudio, indio, indigenismos, Cusco.

\section{The anthropological conceptualization of the indio in Cusco (1942-1973) A framework to understand Anthropology in Peru through diversity}

\begin{abstract}
This article will examine the causes, sources and processes of the anthropological conceptualization of the concept of indio - understood as object of study - taken place in Cusco, from the institutional foundation of the discipline in 1942 to its first great crisis in 1973. In that regard, I propose that said processes of conceptualization were determined by the social and political conditions surrounding anthropologists, in connection to the trending anthropological theory at the time and the institutional situation of the discipline. All this, in relation to specific ideological contexts — such as the indigenisms - and sociopolitical contexts — such as social revolts.
\end{abstract}

Keywords: Anthropology, object of study, indio, indigenisms, Cusco. 
A lo largo del siglo XX las antropologías en Latinoamérica se preocuparon en reflexionar sobre la construcción de los Estados-nación, a partir de la conceptualización de los sujetos nacionales — que también eran objeto de estudio de la antropología-. Estas conceptualizaciones estuvieron condicionadas por el contexto ideológico y sociopolítico, así como también por la condición social y política de los antropólogos, la situación institucional de la disciplina y la teoría que se leía en las aulas universitarias. En ese sentido, comprender nuestra disciplina - léase hacer un balance - desde una perspectiva histórica que entienda las causas y los procesos de conceptualización del objeto de estudio, nos permite también observar y entender los procesos que atravesaron nuestros países desde una dimensión poco atendida hasta ahora.

Lamentablemente en el Perú, pese a tener una extensa producción de balances sobre la disciplina antropológica, son pocas las que se preocupan en este aspecto. Para exponer esta situación, podemos exponerlas en tres grupos. El primero reúne a balances sobre temáticas específicas que se desarrollaron dentro de la antropología. ${ }^{1}$ Estos se caracterizan por realizar un recuento bibliográfico dedicado a la producción antropológica que no necesariamente conversa con sus contextos ideológicos, políticos y sociales, pues se restringen a realizar un estado de la cuestión. Así podemos encontrar a Urrutia (1992), Solano (1993), Degregori (2000), Calvo (2010), Valderrama y Escalante, (2010), Sandoval y Sendón (2012), Cortéz (2015), etc.

Por otro lado, podemos encontrar un segundo grupo de balances orientados a reflexionar sobre la enseñanza de la antropología y su situación institucional. Estos trabajos, además de realizar una revisión bibliográfica sobre la producción antropológica, recurren a la revisión de documentos institucionales como sílabos y currículas - y a la realización de algunas entrevistas y focus group. Aunque este segundo grupo no tiene la misma atención y la misma cantidad de producción que el grupo anterior, podemos mencionar algunos representativos como Rodríguez Pastor (1985), Degregori, Ávila y Sandoval, (2001), Díez (2008), Degregori y Sandoval (2009), Paredes (2015), entre otros. Y finalmente, existe un tercer grupo de balances que, en comparación con los anteriores, es poco atendido, pero posee mayor importancia para este artículo: Montoya (1975), Aramburú (1978), Degregori (2000), Degregori y Sandoval (2007), Degregori y Sandoval (2007), Degregori (2008), Sandoval (2012) y Montoya (2015). Este tercer grupo compuesto por solo cuatro antro1 En este bloque se puede incluir los numerosos balances de peruanistas sobre las temáticas abordadas por
sus escuelas antropológicas en el Perú. 
pólogos, está orientado a pensar a la disciplina desde una perspectiva histórica y con una proyección política, que trasciende la producción académica antropológica y toma en cuenta la situación laboral e institucional de la disciplina, así como los contextos en los que se desarrolla y su relación con el país. ${ }^{2}$ Sin embargo, estos trabajos tienen como punto de enunciación a Lima -invisibilizando procesos regionales como Cusco, Ayacucho o Arequipa, por ejemplo- y se fundamentan solamente en la experiencia del autor y una extensa revisión bibliográfica - dejando de lado el trabajo de campo y la revisión de archivo.

Esta situación evidencia el poco interés que existe en los núcleos académicos de la antropología en el Perú por investigar qué somos, cómo llegamos hasta aquí y hacia dónde vamos como disciplina. En ese sentido, con esta investigación pretendo dos cosas. Primero, cuestionar los balances antropológicos con pretensiones generalizadoras, visibilizando la diversidad de las formas de hacer y entender la antropología en el Perú, particularmente desde el Cusco. Y segundo, proponer un esquema de análisis que nos permita elaborar un relato plural sobre la antropología en nuestro país, que entienda nuestra disciplina desde nuestra diversidad, para a partir de allí entender también la diversidad antropológica en América Latina.

Antes de iniciar el análisis, es importante precisar que la antropología en América Latina, en Perú, pero sobre todo en Cusco, durante el siglo XX, se desarrolló en permanente diálogo con los indigenismos. Para entender la relación entre indigenismo y antropología, planteo la existencia de tres vertientes indigenistas en el plano político-académico que convergen en la fundación de la antropología institucional en el Cusco, en 1942, y se constituyen como el contexto ideológico del desarrollo de la disciplina, hasta 1973. Con esta propuesta no niego las abundantes clasificaciones y estudios previos sobre el indigenismo, por el contrario, los reconozco, pero para fines de la presente investigación propongo un esquema distinto a partir del análisis de sus fuentes teóricas, financiamientos económicos y objetivos.

De esta forma, identifico: i) un "indigenismo regional" financiado por la UNSAAC y por las élites cusqueñas que, desde 1909 en adelante, tuvo como objetivo posicionar a la élite regional cusqueña en el plano nacional, así como también mantener la estructura social del Cusco; ii) un "indigenismo esta-

2 Es importante mencionar que no existe un diálogo entre estos artículos sobre temas puntuales comunes, pues están hechos en momentos distintos y para públicos diferentes. Por ese motivo, no fuerzo un posible debate entre estos autores sobre algunos temas, como el carácter de nuestro objeto de estudio, por ejemplo. 
tal", financiado por el Estado peruano, que desde 1920 en adelante tuvo como objetivo desindianizar al indio para incluirlo a la vida nacional a través del proyecto modernizador; $y$, finalmente, iii) un "indigenismo norteamericanoestatal", financiado por el Instituto Indigenista Interamericano y el Gobierno estadounidense que, desde 1942 en adelante, tuvo como objetivo reunir toda la información sobre los indígenas en América Latina para construir alianzas diplomáticas, pero también, bajo el proyecto desarrollista, elaborar una estrategia de control geopolítico en lo que se denominaba "pólvora comunista", en un contexto de fin de la Segunda Guerra Mundial e inicio de la Guerra Fría. ${ }^{3}$ La influencia de éstos indigenismo —entendidos como el contexto ideológico- en el desarrollo de la antropología en el Cusco las expondremos a lo largo del texto.

\section{Antropología de exploración (1942-1959)}

A diferencia de la discreta fundación del Instituto de Etnología y Arqueología en la Universidad Nacional Mayor de San Marcos en Lima, en 1946, que según Rodrigo Montoya, fue anunciada a través de un aviso pegado en una vitrina de la Facultad de Educación que decía "Va a crearse el Instituto de Etnología y Arqueología, se necesita estudiantes, remítanse a la secretaría". ${ }^{4}$ En Cusco, las noticias de fundación de la Sección de Arqueología y Antropología en la Universidad San Antonio Abad, en 1942, tuvieron gran impacto e incluso causó expectativa nacional ${ }^{5}$ debido, entre otras cosas, a que el Cusco era el escenario más importante para la investigación social que el Perú tenía y por lo tanto recibía la atención de la mayoría de los reflectores y los financistas de las ciencias sociales del mundo. En ese sentido, con el éxito de las investi-

3 Para una mayor comprensión de mi propuesta sugiero revisar el segundo capítulo de mi tesis La ambivalente conceptualización antropológica sobre el indio en el Perú. De la convergencia indigenista a la antropología en el Cusco (1909-1973).

4 Comunicación personal con Rodrigo Montoya 31 de octubre del 2016.

5 Así se leía la noticia en el diario El Comercio de Lima, el 19 de enero de 1942: "El rector de la universidad del Cusco, doctor David Chaparro, ha recibido una atenta nota de The Viking Found con fines científicos, adjuntando la suma de cien mil soles, donado por el filántropo sueco Axel Wenner-Gren, presidente de esa fundación, indicando que será usada [...] sola y expresamente para crear una Sección de Arqueología". El diputado Uriel García gestionó una condecoración tiempo después, pese a que el 27 de enero del mismo año, Axel Wenner-Gren sea duramente cuestionado por su participación en la Segunda Guerra Mundial, como se mencionó en el diario El Comercio de Lima: "Informes oficiales recibidos ayer indican que las autoridades de las Bahamas efectuaron un registro en la residencia de Werner-Gren, en Shagrin La, en busca de instalaciones secretas o instrumentos capaces de ser útiles para el enemigo, con resultados negativos. Esta actuación ha seguido a la inclusión de Wenner-Gren en la lista negra de Estados Unidos". 
gaciones arqueológicas en Cusco, The Viking Found donó a la UNSAAC, en 1941, el monto de cien mil soles para fundar la Sección de Arqueología en la Facultad de Ciencias, pues era inconcebible que en la Capital Arqueológica de América no existiera un centro especializado para la formación y la investigación del antiguo imperio de los incas. Un joven John Rowe, que había llegado a Cusco en 1939 tras cursar sus estudios de Arqueología en la Universidad de Brown e iniciar sus estudios de Antropología en Harvard, fue el encargado de diseñar el plan de estudios bajo el nombre de Sección de Arqueología y Antropología, fiel a la tradición norteamericana. ${ }^{6}$

El Cusco de esos años continuaba siendo una ciudad pequeña que se caracterizaba por tener una precaria estructura urbana, estar sostenida en el sistema económico de hacienda -pese a que, con la llegada del ferrocarril, en 1908, la pequeña industria textil había crecido al igual que el sector artesanaly mantener una estructura social estamental regida por cánones coloniales (Rénique, 1991; De la Cadena, 2004). Sin embargo, la fundación de la primera radioemisora local, en 1936, y el progresivo crecimiento del turismo que se consolidó en 1948 con el establecimiento de vuelos comerciales, significó un cambio importante en el desarrollo de la ciudad que hace un tiempo atrás, producto de la emergencia de las ideas del indigenismo regional, había roto el quietismo intelectual.

Sin embargo, para la década de 1940, el indigenismo en el Cusco se encontraba en un profundo debate conceptual que enrostraba una ruptura generacional y de clase, lo que terminó marcando el carácter de la Sección de Antropología y Arqueología en la UNSAAC. Por un lado, los primeros indigenistas - hijos de las elites cusqueñas reunidos en la generación La Sierra que impulsaron la primera reforma universitaria del Perú en 1909-, que en mayoría fueron cooptados por el proyecto del indigenismo estatal inaugurado en el gobierno de Leguía en 1919, habían adoptaron el proyecto modernizador que significaba la inclusión del indio a la modernidad a partir de su desindianización, manteniendo su preocupación por el rescate de la historia y la cultura indígena. ${ }^{7}$ Y, por otro lado, un grupo de jóvenes indigenistas — surgidos de las clases medias y bajas, reunidos principalmente en el grupo Ande, fundaron

6 Su nombramiento se debió a que rápidamente se había logrado insertar en los círculos académicos del Cusco y constituirse como un miembro destacado debido a su abundante y sistemático trabajo arqueológico en zonas importantes como el Qoricancha, la zona de los chanapata y los killiki (Valderrama y Escalante, 2010).

7 Las figuras más resaltantes de esta primera generación son Luís E. Valcárcel y Uriel García. Para una mejor comprensión de esta generación Tamayo 1980; Pando 2009, Aparicio 2012. 
las primeras células apristas y comunistas en el Cusco-, que criticaba a los primeros, pues sostenían que no se debía limitar la labor intelectual al rescate de la historia y la cultura del indígena muerto, sino que era necesario mirar al "nuevo indio" que ellos mismos encarnaban. ${ }^{8}$

Estas diferencias de las propuestas generacionales fueron las parteras de la antropología institucional en el Cusco, pues, por un lado, los viejos indigenistas sostenían que se preste mayor atención a los cursos de Antropología Física, Arqueología, Paleontología y Lingüística, alegando que brindaría las herramientas suficientes para investigar la historia y la cultura de los incas que había heredado pobremente el indio, y por otro lado, los jóvenes indigenistas exigieron que dentro del plan de estudios se incluya el curso de Folklore, pues argumentaban que era más importante estudiar la danza, la música, las artes, y todo lo concerniente al indio vivo. De esta forma, ambas generaciones de indigenistas encontraron un espacio donde desarrollarse, ya no políticamente - porque el contexto nacional los había relegado mediante los discursos de modernización - , sino ahora académicamente, como un refugio de resistencia tras los intensos debates de años anteriores. Es bajo esta dicotomía - de complementariedad desigual — que se formaron las primeras generaciones de antropólogos que fundamentalmente eran hijos de las élites cusqueñas apris$\operatorname{tas}^{9}$ pertenecientes a familias de comerciantes como los Núñez o hacendados como los Bejar, Alencastre o Fuentes.

El marco teórico que dio forma a la antropología en el Cusco fue el culturalismo - caracterizado por la profunda critica al concepto de raza, sus mecanismos esencializadores al momento de conceptualizar a su objeto de estudio y la forma de entender la aproximación del investigador hacia el indígenabajo el que Rowe se formó en Estados Unidos y el que llevó a Cusco como novedad académica. La forma en cómo se consolidó el culturalismo norteamericano, con la disputa indigenista y las nociones para entender y reproducir las estructuras sociales del Cusco - por parte de los jóvenes estudiantes cusqueños-, fue el sello de agua de la antropología de esas décadas y significó varios conflictos poco visibilizados hasta ahora, que merecen nuestra atención.

8 En esta segunda generación de indigenistas resaltan los nombres de Carlos Valer y Julio Gutiérrez. Para una mayor referencia sobre esta generación Lynch 1979; Gutiérrez 1988; Cuadros 1990.

9 La primera promoción de estudiantes estuvo conformada por Óscar Núñez del Prado, su esposa Luisa Béjar de Núñez del Prado, Guillermo Fuentes Díaz, y Gustavo Alencastre. Escalante y Valderrama (2010) señalan que también formaron parte de esa promoción Estela Bocángel (sic) y el padre Heredia, mientras Flores (2013) agrega a Carlos Kalafatovich. Sin embargo, al no existir registros institucionales sobre los primeros años de la Sección de Antropología y Antropología, no podemos dar certeza de la participación de estas personas en la primera generación de antropólogos. 
El primero de ellos nos interpela sobre cómo los antropólogos cusqueños - provenientes de una élite regional que justificaba en términos raciales la estructura social que excluía al indio- leyeron y entendieron al culturalismo, pues aceptar por completo la perspectiva culturalista significaba cuestionar la estructura social y su funcionamiento, algo que no hicieron estos primeros antropólogos. Por lo que más allá de prestar atención hacia la crítica del concepto de raza - porque, como explica De la Cadena (2004), la élite cusqueña sostenía el discurso racista en la intimidad-, se otorgó mayor énfasis a los elementos esencializadores para conceptualizar a su objeto de estudio y a las herramientas metodológicas para estudiarlo. De esta forma, la antropología en el Cusco que había heredado del indigenismo al indio como objeto de estudio, reprodujo los mecanismos de conceptualización y descripción que el culturalismo tenía en su caja de herramientas y que los profesores, principalmente norteamericanos, enseñaban en aulas.

Para los antropólogos culturalistas, el acercamiento al indígena necesitaba de un viaje interminable a territorios recónditos, por lo que la construcción del objeto de estudio pasaba por la identificación de un otro completamente distinto y lejano - física, fenotípica y temporalmente- Sin embargo, esta situación era distinta en Cusco, pues el antropólogo convivía con su objeto de estudio, ya que era el indio quien trabajaba en su hacienda o le generaba conflictos por límites territoriales. Aun así, apegados a la formación teórica que recibían, los antropólogos cusqueños se fueron en busca de los pueblos indígenas que todavía podrían conservar ciertas características de sus antepasados, para que intenten esbozar una idea sobre el desarrollo de la cultura en los Andes con una clara preocupación por estudiar las permanencias culturales a partir de un esquema de estudio de una comunidad total y a su vez desarticulada de las demás, diferenciando así entre tradición/modernidad, campo/ ciudad (Pajuelo, 2000).

Un claro ejemplo del cumplimiento de este rito de paso antropológico es la minuciosa atención y la larga descripción que hace Óscar Nuñez del Prado (Flores, 2005, pp. 200-201) al difícil viaje que realizó junto a su equipo para llegar a Q'ero, en la más famosa expedición de esta primera etapa: ${ }^{10}$

10 Q'ero, en ese momento era un conjunto de ayllus indígenas que aglutinaba aproximadamente 5000 personas y que mayoritariamente se ubicaba en la provincia de Paucartambo dentro de una hacienda la Hacienda Azul, conocida ampliamente por los métodos de horca y cuchillo que practicaba el hacendado, en el límite entre los andes y la selva. La expedición tomó gran importancia porque se la bautizó como "La expedición al último ayllu inca", se realizó en 1955 bajo el auspicio del diario La Prensa y estuvo compuesta por un equipo diverso de cuatro investigadores, dos ayudantes de investigación, un fotógrafo y un periodista. 
Por encima de todo contratiempo, la expedición partió del Cusco el 24 de julio de 1955, cubriendo aquel día, la primera etapa del viaje en un camión, hasta la capital de la provincia de Paucartambo. Al día siguiente salimos a caballo por un buen camino de herradura que, en dirección contrario al río Mapacho, va en suave acenso por su margen derecha, hasta la confluencia del río Kusipata en que el camino se desvía hacia el sur para conducir a la hacienda del nombre de dicho río, aproximadamente a 18 kilómetros de Paucartambo. Aquí acampamos, con el propósito de organizar la observación de una fiesta indígena que habría de realizarse al día siguiente. Dejamos con este objeto parte del personal y proseguimos la marcha el día 26. A medida que avanzamos, las montañas aumentan gradualmente de altura y las aguas del Kusipata se despeñan con violencia. [...] Después de una hora de marcha aparece hacia el este la azulada cadena de cuchillas del Waman-qaqa que es preciso transmontar por una senda rocosa y escarpada. [...] Después de esta jornada que cubre aproximadamente 36 kilómetros, armamos las tiendas en un abrigo a 3600 metros de altura. A las ocho de la mañana del día siguiente, pudimos continuar la marcha, ascendiendo por un sendero sumamente empinado, por la margen derecha del Willkanota, para alcanzar Willkayunca, un valle de origen glaciar que se abre en un gran círculo coronado de elevados y negros picos que es forzoso tramontar. La marcha se hace lenta y difícil, por lo áspero y empinado del camino que obliga a hacer el ascenso a pie. Pronto estamos ante el espectáculo de un circo, que de acuerdo a las observaciones del doctor Escobar, resulta ser de origen glaciar, del que descienden arenas de dicho origen, morrenas y cantos erráticos. [...] llegamos al paso del Willka-qunqa Q'asa apachita, cerca de los 5 mil metros, y se abre entre nosotros un paisaje extraño que nos sobrecoge. Iniciamos ahora un largo y tortuoso descenso, y a las 5 de la tarde del 27 de julio llegamos al pueblo.

El establecimiento de este rito de paso antropológico dio paso a que el antropólogo genere una doble esencialización sobre el indio, pues además de la estrategia escencializadora que tenía la antropología para conceptualizar a su objeto de estudio, el indigenismo regional le heredó el esencialismo al que había recurrido para reivindicar el pasado histórico y cultural del indio perdido en la historia. Por ese motivo, en esta primera etapa no es extraño encontrar narraciones como las que realiza Núñez del Prado (Flores, 2005, pp. 82-83), cuando describe al indio de Q'ero:

[El indio es de] una complexión más bien delgada y esbelta, salvo la gran extensión del tórax que hace armonía con las pantorrillas que parecen estriarce por músculos nervudos en una estatura media de 1.60 para los varones y 1.55 en las mujeres. Es de mentalidad clara y vivaz, ingenuo y franco al mismo tiempo, habla poco y se siente mortificado cuando se le quiere hacer repetir lo que ha dicho. Es severo en su conducta, parco en su trato, pero sumamente hospitalario con el viajero. Desconfía profundamente del blanco o el mestizo, pero no muestra hos- 
tilidad hacia él. Su cortesía le obliga a beber la primera copa con que se lo invita, pero, rechaza abiertamente el alcohol si no es en las tres únicas festividades de su pueblo. Ha hecho un culto del trabajo y la expresión máxima de sus valores. En el sentido estricto de la palabra, no tiene vicios, salvo que se quiera imputar como tal el aspecto muy discutible de la masticación de la coca en la que se inicia entre los 18 y 20 años, practicándola mesuradamente. La chicha no es su bebida cotidiana, sino que está señalada para muy reservadas oportunidades, especialmente a los ritos de fertilidad del ganado. Vive nutrido de tradiciones, leyendas y mitos que explican el mundo que lo rodea, los orígenes del maíz, la coca, los animales; la génesis de su música y su danza que, según él, fueron copiadas del kios, ave que sirve de inspiración a muchas de sus canciones y relatos. Su poesía sumamente hermosa, toma como temas fundamentales, las bellezas de la naturaleza y se manifiesta en canciones que anualmente deben ser renovadas por un poeta designado oportunamente. [...] Su observación del mundo sideral le permite reconocer e identificar varios astros vinculados a su mitología y creencias. Guarda un conjunto de conocimientos que incluye el manejo de los khipus o registro de anudaduras, por lo menos en tres variedades. [...] Hasta hace cerca de quince años, llevaban los hombres la cabellera en largas trenzas, que al decir de ellos los ostentaban como un símbolo de su estirpe inca, hasta que cayeron bajo las tijeras del patrón que las hizo cortar empleando la fuerza.

Pero esta conceptualización del indio, que en este primer momento respondía a una necesidad antropológica para conceptualizar el objeto de estudio y a una necesidad política de mantener el pasado histórico y cultural de los incas, también estuvo marcado por la relación tutelar de amor-desprecio del hacendado hacia el indio que los antropólogos tenían interiorizado y que se vio reforzado, hasta cierto punto, por la forma de relación y aproximación - también tutelar - que proponía la antropología para que el investigador pueda recabar información del indígena. Así lo evidencia Demetrio Roca Huallparimachi, alumno de Antropología en esta primera etapa y una excepción dentro de la constante general de la condición social de los estudiantes de esos años, debido a que fue el único universitario de los seis hijos de una campesina viuda de la provincia de Anta:

Los profesores hablaban pues, hacían sus clases hablando de los campesinos, pero en la práctica no hacían nada. Se ponían a hablar entre las cuatro paredes de las aulas de la universidad de cuando iban al campo, pero luego decían que los campesinos eran borrachos, que los campesinos [eran] analfabetos, y eran hacendados que tenía gente campesina dentro, gente trabajadora de su finca. Eso pasaban porque iban a trabajar al campo [a hacer etnografía], pero tonteaban, caminaban, miraban, escribían, tomaban apuntes de lo que veían o lo que oían, pero no vivían. Miraban, miraban, se paraban al borde del campo en donde la gente 
estaba trabajando, delante. Una que otra vez, o de vez en cuando, o las veces que podían hablar, conversaban con el campesino. En cambio, yo me metía a trabajar con ellos, pues, pero conversando en quechua; era muy importante saber hablar y escribir en quechua. ${ }^{11}$

Esta relación tutelar hacia el indígena, que también estuvo influenciada por la filiación, principalmente aprista de los antropólogos — pues había que lucha por ellos, pero sin ellos_- fue la que, junto al carácter esencializador propio del indigenismo y la antropología, caracterizó a la antropología en el Cusco en este primer momento y le brindó un sello conservador que le impidió observar los cambios sociales que se estaban gestando y estallaron años después.

\section{Antropología aplicada (1959-1968)}

Esta forma de entender la disciplina - como una antropología del rescate - y la manera de conceptualizar al objeto de estudio - como un indio prístino cuasi perfecto que mantiene la grandeza de su pasado- cambia abruptamente cuatro años después, en 1959, cuando inicia el proyecto de antropología aplicada en la comunidad de Kuyo Chico, ${ }^{12}$ que sería el referente más importante de la antropología en el Cusco durante sus casi diez años de vida.

Esto se evidencia con claridad a lo largo del informe del proyecto Kuyo Chico (Nuñez del Prado, 1970), donde, por ejemplo, el indio ya no mantiene su tradicionalidad, al contrario, es un indio corrompido y empobrecido por las haciendas y las ciudades de mestizos. Tampoco es un indio de "mentalidad clara o vivaz", sino es un indio que ha naturalizado las relaciones de opresión que tiene con otros grupos sociales. Es medroso, siempre está tiste y no tiene capacidad de pensar por sí mismo un posible cambio. Tampoco es esbelto ni mucho menos ha hecho del trabajo un culto; por el contrario, es débil y mal alimentado. Ya no guarda sus conocimientos ancestrales como los Q'ero, ni mucho menos mantiene su tradición religiosa apartada de la occidental, sino ha adquirido prácticas mestizas que lo único que han logrado ha sido desarrollar un sentido de vergüenza y rechazo a su cultura. Tampoco es un indio que tiene una lógica de autosubsistencia, sino, está ubicado al final de la cadena de mercado porque económicamente depende de la ciudad que compra

11 Entrevista a Demetrio Roca Huallparimachi, 11 de febrero del 2017.

12 La comunidad de Kuyo Chico se encuentra en Pisaq, dentro del valle del Urubamba, en Cusco, uno de los valles más ricos del Perú. 
su producción a los precios que cree justo el mestizo. Es decir, mientras los q'ero eran el último ayllu inca del cual se podía sostener una reivindicación del pasado gloriosos andino para construir una nación, y por lo tanto merecía un arduo trabajo de rescate por los antropólogos; los kuyinos eran todo lo contrario, por lo que la antropología, debía ser una herramienta para que el antropólogo, cual hermano mayor, le muestre el camino del desarrollo y le ayude a andar en él.

Este cambio se debe, en principio, a que, producto de la relación con otras instituciones de ciencias sociales - como el IEP, la UNMSM, El Instituto Indigenista Peruano y el proyecto Vicos-, la UNSAAC acogió a la antropología aplicada como paradigma teórico y disciplinario, pese a que no existía un correlato teórico directo entre el culturalismo y la antropología aplicada, sino que, por el contrario, significaba un salto de una teoría antropológica a un proyecto de desarrollo que el indigenismo norteamericano estatal había gestado, de la mano de otras ciencias sociales, para, primero, controlar los cambios sociales internos que el país del norte tenía en plena guerra; y luego, durante la Guerra Fría, generar un proceso de acercamiento gubernamental con el resto de países latinoamericanos a través del proyecto desarrollista que Truman había iniciado a finales de la década del cuarenta para combatir el comunismo, teniendo como una de las herramientas principales al Instituto Indigenista interamericano.

Por ese motivo - para mantener frescura académica, obtener financiamiento y por lo tanto mayor trabajo - la antropología dejó de entender al indio dentro de una comunidad prístina que mantenía su economía, historia y cultura, alejada de la civilización y lo conceptualizó como un indio que resistía toda la presión de la estructura social que se erigía sobre él, en un país dual que lo excluía sistemáticamente. Hasta aquí, una visión más cercana a la realidad del indio en el Perú de esos años, sin duda. Sin embargo, para los antropólogos cusqueños, el problema fundamental del indio era su falta de acceso a servicios básicos — principalmente educación y sanidad—, su falta de producción — para que pueda incluirse al mercado - y el desconocimiento de la legislación que tenía a su favor; por lo que la solución pasaba por la obligación del antropólogo para acercar al indio a estos tres elementos y así ayudar a su inclusión a la vida nacional, vía inserción del mercado. Núñez del Prado (1970, p. 69) nos cuenta con mayor precisión: 
Es evidente que la inferioridad económica, el desconocimiento de sus derechos y la fuerte presión social existente no permiten al indígena recurrir oportunamente a la abundante legislación que lo protege; de ahí que sean presa fácil de los mestizos sin escrúpulos, acostumbrados al trajín de estrados judiciales, despachos de autoridades y dependencias policiales

Llama la atención que, para Núñez del Prado y la antropología, el problema del indio no era el problema de la tierra, como lo había planteado González Prada o Mariátegui a inicios del siglo XX, sino, era un problema de conocimiento de sus derechos y acceso a ellos. Más aún, si tenemos en cuenta que esta lectura se realizó en un contexto de continuo levantamiento indígena por la tierra y contra el abuso de las haciendas en territorios cercanos al proyecto. ${ }^{13}$ Recordemos que el Cusco en estas décadas, todavía era una región sostenida económicamente por el sistema de hacienda, pues, según el Primer Censo Nacional Agropecuario de 1961, en el Cusco existían 64446 unidades agropecuarias con tierras, ${ }^{14}$ que abarcaban un total de 1748151.1 hectáreas, de las cuales 1420905.6 hectáreas se dividían entre 469 unidades agropecuarias mayores a 500 hectáreas. Mientras 14089.6 hectáreas pertenecían a 28097 unidades agropecuarias de menos de una hectárea. Es decir, en tan solo 469 unidades agropecuarias se concentraba el $81.3 \%$ del total de tierras, mientras que entre 28097 unidades agropecuarias se disputaban el 1.61\% de la tierra.

Pero esta lectura no debería sorprender pues la mayoría de estudiantes y profesores de antropología en el Cusco, al igual que en la etapa anterior, pertenecían a las élites cusqueñas - muchos de ellos pertenecientes a familias de hacendados—-, que, antes de revolución y repartición de tierras, pensaban en otros mecanismos de ayuda al indígena y reformas agrarias que en lo posible no atenten contra el patrimonio familiar. Esta situación social queda más clara con el testimonio familiar de Jorge Flores Ochoa estudiante de los últimos ciclos de la carrera y posteriormente ayudante de Óscar Núñez del Prado:

Mi madre, Laura Ochoa Pacheco, era ama de casa y como era la mayor de su casa heredó unas haciendas que sus padres tenían en Urubamba y también en

13 La década de 1960 estuvo caracterizado por la gran cantidad de luchas indígenas por la tierra, principalmente en el sur del Perú. La más grande de ellas fue la toma de tierras de La Convención, en Cusco, a 200 $\mathrm{km}$ del proyecto de antropología aplicada de Kuyo Chico, liderada por Hugo Blanco y que tuvo su mayor auge en 1962.

14 Según el Primer Censo Nacional Agropecuario de 1961, la unidad agropecuaria con tierras es "el predio o conjunto de predios, estén o no contiguos, pero que en conjunto formen parte de la misma unidad técnico-económica, de la que se obtienen producciones agrícolas, ganaderas, o mixtas, bajo la dirección de un productor" (p. II). 
Cusco. Su padre tenía una cantidad de haciendas por todos lados; yo creo que no he tenido la oportunidad de saber cuál es el nombre de todas las haciendas. Pero esas haciendas que heredó mi madre estaban en Machu Picchu; iba desde el kilómetro treinta hasta mucho más allá de Machu Picchu. Era una hacienda un tanto improductiva, porque estaba en esa zona, allí era cabecera de Amazonía. [...] Entonces, y esto da gracia recordar, el caserío de la hacienda de mi madre es lo que ahora es Machu Picchu pueblo, Machu Picchu Estación. [...] Pero las únicas tierras que conocí eran las de Urubamba, porque casi siempre en las vacaciones por dos meses, tres meses íbamos a Urubamba porque ahí mi madre tenía hermanos que tenían sus tierras, sus casas, entonces pasábamos ahí los fines de año. [...] Mi padre, Miguel Ángel Flores, era abogado y tenía relaciones con Paucartambo porque los Flores tenían varias haciendas en Paucartambo, [...] [pero] no íbamos a las haciendas de mi papá, porque llegar a Paucartambo era un poco más complicado. Hasta hoy día Paucartambo no es de fácil acceso y en esa época era más difícil de llegar. [...] Pero nosotros ya vivíamos en el Cusco. [...] Al principio en la casa de los padres de mi madre, que estaba por Nueva Alta. Era una casa inmensa que salía de una calle y llegaba hasta la otra, tenía dos espacios, uno era de los dueños de casa, y siempre había habitaciones que se alquilaban a personas de otro nivel, podían ser carniceros, zapateros, vendedores del mercado, cosas por el estilo. Y el otro espacio era para vivir. Entonces vivíamos ahí, pero después nos fuimos a la casa de la calle Fierro, y luego mi madre compró una casa en la calle Chaparrro, y de la calle Chaparro no nos movimos hasta hace pocos años aquí a Huancaro. [...] Nosotros también teníamos [servidumbre], porque mi padre hizo una defensa de unos parientes de una hacienda muy valiosa en la zona de Anta y se enfrentó al gamonal más temido de la época, el señor Luna, y como ganó el juicio, entonces los parientes por agradecimiento dijeron: "Vamos a enviar todas las semanas un pongo". [...] [Además] teníamos sirvientas, creo eran cinco, y todas le ayudaban a mi madre a lavar, cocinar y hacer mandados de la casa. ${ }^{15}$

La situación privilegiada de la mayoría de los antropólogos — que sostenía la conceptualización del indio producida por la antropología en ese momento--, empató con la situación institucional de la Sección de Antropología marcada por la opción política de sus integrantes. En esos años, la UNSAAC vivía un ambiente político caldeado como el escenario político peruano en general. La Juventud Aprista Peruana (JAP), en la década del cincuenta, había logrado el control institucional de la universidad junto con el Centro Universitario Reformista Independiente (FURI). ${ }^{16}$ Sin embargo, en 1962 irrumpió el Frente Estudiantil Revolucionario (FER) como fuerza política dentro de la univer-

15 Entrevista a Jorge Flores Ochoa, 10 de enero del 2016.

16 El FURI era un grupo más conservador frente al APRA. Entre sus integrantes encontramos Valentín Paniagua y José Tamayo Herrera. 
sidad, ya que era inevitable que la izquierda — que cada vez adquiría mayor fuerza en el escenario político cusqueño - tenga injerencia en la UNSAAC.

Pese a la alta politización de la comunidad universitaria — principalmente cercana a la izquierda - la Sección de Antropología se mantuvo casi aislada, como una burbuja dentro de la universidad, debido a que era una sección nueva, con pocos alumnos ${ }^{17}$ — de mayoría masculina —, ${ }^{18} \mathrm{y}$ donde "se priorizaba el estudio" antes que la política ${ }^{19}$, aunque gran parte de los jóvenes y profesores mantenían una admiración y cercanía con el APRA que ya había abandonado su tradición radical y había dado un giro hacia la derecha (Zapata, 2016), pues tenían a cuestas la alianza APRA-UNO y Víctor Raúl Haya de la Torre sostenía que "En el Perú no se trata de quitar riqueza al que la tiene, sino de crear riqueza para el que no la tiene". ${ }^{20}$

Por ejemplo, Abraham Valencia, estudiante de Antropología a inicios de la década de 1960, cuenta que la mayoría de sus compañeros eran apristas, incluso él militó en el APRA al igual que Jorge Flores Ochoa, pero lo abandonó tras una marcha en su primer año de universidad donde salió herido. ${ }^{21}$ De igual forma, Rodolfo Sánchez Garrafa, estudiante de Antropología, a mediados de la década del sesenta, también cuenta que la mayoría de sus compañeros tenían cercanía al APRA, pero no recuerda algún tipo de militancia explícita. ${ }^{22}$ Pero quien grafica de mejor forma esa admiración y cercanía de los estudiantes con el APRA es Rina Cornejo:

17 Rina Cornejo (entrevista del 21 de junio del 2017) y César Vivanco (entrevista del 15 de agosto del 2016), estudiantes de antropología en esos años, coinciden en que el alumnado de Antropología no pasaba de las ciento veinte personas.

18 Ingresaron treinta aproximadamente [a Antropología], de los cuales éramos dos mujeres, Gloria Miranda y yo. Pero ella después se fue a estudiar Arquitectura, porque recuerdo que estaba la esposa de Hugo Bonet, pero ella se fue a Historia. Pero ya en tercer año, para pasar a Antropología éramos treinta y solo dos mujeres. [...] Al doctor [Demetrio] Roca lo recuerdo porque nos llevaba al campo, pero era muy duro, a nosotras las mujeres nos trataba mal, nos decía "Carajo, a que se han metido a profesión de varones". Recuerdo cuando hemos ido a Chahuaytiri, hemos ido a Kuyo Chico en carro y de Kuyo Chico hemos dormido ahí, hemos ido a pie cargando nuestras mochilas hasta Chahuaytiri y era un cerro bien parado. Contrataron burros los varones, pusieron su carga y se fueron caminando y nosotras, las mujeres, llevando nuestra mochila. Te juro que yo vi la muerte cerca, no podía ni respirar, así como él nos decía "Carajo...", yo también decía "Carajo yo voy a seguir y le voy a demostrar lo que somos". Yo era bien recia. Llegado a Chahuaytiri y allí a trabajar. Nos decía siempre "A qué se han metido a profesión de varones". Entrevista a Rina Cornejo el 21 de junio del 2017.

19 Rina Cornejo (entrevista del 21 de junio del 2017) y Rodolfo Sánchez Garrafa (entrevista del 07 de agosto del 2018) caracterizarían así a la Sección de Antropología.

20 "Discurso del reencuentro", 20 de mayo de 1945.

21 Entrevista a Abraham Valencia el 01 de diciembre de 2016.

22 Entrevista a Rodolfo Sánchez Garrafa el 07 de julio de 2018. 
A mí me decían "Ahí viene la aprista", pero valgan verdades, yo no era aprista, pero votaba por el APRA en el Centro Federado de la facultad. Nosotros íbamos a escuchar los debates en el patio de la universidad, pero esa vez con mi corazoncito, no porque yo fuera aprista, sino porque tenía mucha amistad con los apristas. [...] [En antropología un aprista era] Danilo Pallardel, él era mi compañero y fue dirigente aprista. Por ejemplo, él siempre ha estado encabezando. En mi grupo ninguno militaba, pero, por ejemplo, [Víctor] Núñez del Prado yo tenía entendido que votaba por el APRA. Todo nuestro grupo. Pero nunca nos inscribimos, solo veíamos. [...] Éramos más de chacota: "Sí, que viva el APRA", "iQue viva!"

Y a continuación brinda un excelente testimonio sobre la relación entre la filiación política y la academia, además de la forma en cómo se manejaba institucionalmente Antropología:

Con las notas no sé qué tanto tuvo que ver la filiación, pero noté que si había cercanías. Entonces son cosas que van incomodando. Pero sí había una relación entre política y academia, de apoyo, de privilegio, de prebendas. Y la escuela estaba manejada por el APRA y la izquierda en distintos momentos. En esos años, ya cuando yo estaba egresando recién ubicaba, —¡Ay, dios mío!, es un poco complicado decirte - Cuando yo he estado — no sé cómo decirte...- Era el APRA, pues, pero después la izquierda. Había ese conflicto, la izquierda traía más gente y el APRA también. Así funcionaba. Bueno, pero en concreto, el que manejaba todo era Óscar Núñez del Prado, la facultad y más Antropología, lógicamente. Influía muchísimo para traer docentes.

Esta convergencia conservadora entre el discurso de la antropología aplicada - que envolvía el proyecto del indigenismo norteamericano estatal- y el perfil socio político de la mayoría de estudiantes y profesores de la Sección de Antropología de la UNSAAC — que reproducía las formas de relación señoriales propias de la sociedad cusqueña de esos años-, consolidó una manera conservadora de conceptualizar al indio y entender a la disciplina antropológica, ajena a los procesos de cambio radical que se vivía en el Perú y principalmente en el Cusco. Dando como resultado, entre otras cosas, la inexistencia de cursos y la inadmisión de profesores que pudieron vislumbrar debates sobre la situación conflictiva y de profundo cambio que atravesaba el Cusco y el país. Experiencia diametralmente opuesta a la ocurrida por los mismos años en la UNMSM, donde ya había un pronunciado sector de la enseñanza antropológica preocupado por entender los cambios de la sociedad peruana

23 Entrevista a Rina Cornejo el 21 de junio del 2017. 
desde una perspectiva marxista. ${ }^{24}$ Esto debido a que en la UNMSM existía una situación política distinta a la UNSAAC, pues en esos años el APRA tenía el poder dentro de la universidad, con Luis Alberto Sánchez como rector, por lo que la Escuela de Antropología era vista como un espacio de "rojos comunistas", que acogía a los militantes del Movimiento de Izquierda Revolucionaria y de Vanguardia Revolucionaria, mientras en la UNSAAC, la Sección de Antropología era vista como el "reducto aprista" de la universidad.

Esta situación, nos permite entender mejor las diferencias existentes entre ambas experiencias en cuanto al desarrollo institucional de la disciplina, que desembocó, en el caso de la UNMSM, en un temprano ingreso de una perspectiva marxista en la antropología, mientras que en el UNSAAC tuvo una inserción posterior. De esta forma, podemos concluir que mientras en la UNMSM los proyectos de investigación habían iniciado funcionalistas y gringos, pero terminaron dependentistas y cholos (Degregori, 2000); los proyectos de investigación en la UNSAAC habían terminado tan culturalistas y gringos como habían empezado. ${ }^{25}$

\section{3. ¿Hacia una nueva antropología? (1969-1973)}

A fines de la década de 1960, el protagonismo político de la izquierda en el Perú, pero particularmente en el Cusco, aumentaba pese a las constantes divisiones partidarias. La irrupción del gobierno de Velasco, en 1968, si bien fue un freno de mano para las izquierdas (Franco, 1983), también avivó el ambiente político donde la discusión sobre el carácter de la sociedad peruana y el modo de producción que imperaba en el Perú, tomó importancia. En ese sentido, los estudiantes de izquierda de la UNSAAC, tras abandonar su activa labor en el campo ayudando a la organización del movimiento campesino -debido a la persecución política que sufrieron en el gobierno de Belaunde (1963-1968)-, se refugiaron en las aulas universitarias y se concentraron en la

24 Por ejemplo, Jorge Bravo Bresani dictaba un curso desde la perspectiva marxista, teniendo como tema a "Marx y el concepto del hombre", Aníbal Quijano en 1965 ya dictaba un curso de marxismo en Sociología y Rodrigo Montoya, en 1968, tras su retorno de Francia, dictó un curso dedicado íntegramente a antropología y marxismo.

25 Es importante mencionar como otra diferencia que en la UNMSM se había fundado la Escuela de Sociología, y esto permitió cierto diálogo entre las disciplinas. En la UNSAAC no existió esta posibilidad, debido a que no había una Sección de Sociología. 
pugna por el poder dentro de la universidad que ya había adquirido otro perfil social.

Los profundos cambios durante la década de 1960, generaron que la sociedad cusqueña migrara de una estructura estamental a una de clases, y la UNSAAC había atestiguado este cambio con el ingreso masivo de estudiantes altamente politizados y principalmente migrantes, provenientes de sectores medios, a las aulas universitarias. Los estudiantes de Antropología de aquellos años a los que logré entrevistar coinciden en describir estos cambios en el ambiente universitario donde el Comedor Universitario adquiría protagonismo como espacio de la socialización estudiantil. Vemos entonces a una nueva generación de estudiantes de Antropología con un alto grado de politización que tenía cercanía o militaba mayoritariamente en la izquierda - Patria Roja y Vanguardia Revolucionaria, principalmente $-{ }^{26}$ y una minoría que todavía mantenía cercanía con el APRA y la Democracia Cristiana. Esto se debe, en parte, a que, un gran sector de estudiantes de Antropología de esta nueva generación, pertenecían a familias de clases medias y bajas que participaron activamente en la toma de tierras y en la vida política durante la década de 1960.

Este escenario generó, por parte de los estudiantes, una serie de cuestionamientos hacia la vida institucional, los profesores y los cursos que recibían. Varios de los entrevistados coinciden que era una etapa en la que los estudiantes se dieron cuenta de la distancia existente entre la realidad, sus lecturas marxistas y la antropología que se les enseñaba, pues argumentan que, mientras en los manuales marxistas encontraban elementos para entender mejor los cambios que estaban viviendo, la teoría antropológica no se orientaba en absoluto a resolver esas inquietudes. Óscar Paredes Pando retrata esta situación de la siguiente forma:

Nosotros buscábamos más cursos de economía y los profesores nos decían "pero ahí están los libros de Herskovitz". Pero esos contenidos a nosotros no nos permitían tener elementos teóricos para entender el problema social, el problema local, regional. [...] También recuerdo el curso de Folklore. Nosotros teníamos nuestro propio concepto de folklore. Para nosotros eso era parte de la superestructura [...], todo a contra corriente de lo que se daba en la facultad. Ese curso lo dictaba el doctor [Demetrio] Roca [Huallparimachi] y le decíamos: "Lo que pasa, doctor Roca, estas cosas responden y están ubicados en la superestructura de la sociedad. Si nosotros no vamos a conocer bien la sociedad, no vamos a

26 Por ejemplo, Óscar Paredes Pando fue dirigente de Patria Roja y David Ugarte Vega Centeno fue su similar en Vanguardia Revolucionaria. Ambos grupos, aunque opuestos en el debate sobre el modo de producción de la sociedad peruana, fueron fundamentales en la reforma institucional de Antropología en 1973. 
entender esos cargos; las fiestas religiosas, es una especie de subproducto", le decíamos. Y el profesor se ponía a leer textos muy simplificados de materialismo histórico y dialectico, y para nosotros generaba un nivel de sonrisa porque qué íbamos a hacer, era nuestro profesor. ${ }^{27}$

Pero también se evidenciaron diferencia en la forma en cómo la antropología se aproximaba al indio y cómo los estudiantes, por su militancia, lo hacían. Mientras para la antropología el indio continuaba siendo un objeto de estudio muy distante al investigador — producto de la formación teórica que recibían-, los estudiantes lo concebían como su "compañero" de lucha para generar cambios. Esto significó que, incluso, la forma en cómo se debía tomar en cuenta la opinión del objeto de estudio dentro de las investigaciones, estaba en proceso de cambio. Carmen Escalante da luces al respecto:

Dentro de las aulas muchos de los profesores seguían utilizando el término "indígena", pero nosotros en esa etapa los llamamos "campesinos" y también "compañeros". Dentro de las aulas eran los objetos de estudio, eran "los informantes", en cambio para nosotros eran "los narradores". ${ }^{28}$

Estas diferencias abrieron paso para que la organización estudiantil adquiera protagonismo y genere cambios importantes dentro de la institución. De esta forma, se empezaron a dictar nuevos cursos, ${ }^{29}$ así como también a cambiar el sentido a algunos ya existentes con nueva literatura. Sin embargo, estos procesos de cambio se toparon con una plana docente muy reducida que reproducía la antropología a la que criticaban los estudiantes, ${ }^{30}$ por lo que se inició un proceso de inclusión de nuevos profesores cercanos al cambio que los alumnos esperaban. ${ }^{31}$ Este proceso llegó a su punto más alto cuando los estudiantes lograron convocar a Darcy Ribeiro, Alfredo Torero, Walter Quinteros, Rodrigo Montoya y Aníbal Quijano para dar charlas sobre la realidad nacio-

27 Entrevista a Óscar Paredes Pando, 12 de agosto del 2016.

28 Entrevista a Carmen Escalante, 27 de enero del 2017.

29 Cabe precisar que pese a los intentos para virar hacia una nueva forma de antropología, en la nueva currícula se evidencia que se mantuvieron las venas culturalistas de años anteriores. Así podemos encontrar los cursos de Estructura Social, Ideología y Cultura, Antropología Política, Modelos organizacionales en la sociedad peruana, Legislación y Reforma Agraria, Materialismo Dialético e Histórico y Dominación y Dependencia, junto a los cursos de Folklore en el Perú, Paleontología, Cambio y dinámica socio-cultural, Antropología Física, Sociología del Desarrollo, Hominización y Raciación. En Oficina de Registro Central de la Universidad Nacional San Antonio Abad del Cusco. Programa Académico de Antropología 1975.

30 Jorge Flores Ochoa, Óscar Núñez del Prado, Demetrio Roca Huallparimachi, Aurelio Carmona, Abraham Valencia, entre otros.

31 Ingresó a la plana docente Jorge Villafuerte, Marco Villasante, Jorge Sánchez, entre otros, más cercanos a las ideas y solicitudes estudiantiles. 
nal y la situación de las ciencias sociales frente a ella - en los primeros años de la década de 1970 - y cuando se realizó la primera reforma administrativa más grande hasta ese momento, — que obligó a cerrar la institución durante algunos meses en 1973.

Pero este periodo no significó un triunfo de la "antropología marxista", ni de los estudiantes o, en última instancia, de la disciplina misma. El momento de efervescencia pasó al igual que los alumnos que la impulsaron, mientras los profesores se quedaron. No se tendieron puentes entre la antropología conservadora que se enseñaba y el marxismo de manual reivindicado por el movimiento estudiantil. Por el contrario, la comunidad académica en el Cusco se dispersó producto de las disputas políticas que se agudizaron con el avance de la década de 1970. Óscar Paredes Pando ejemplifica de forma excelente este problema:

Profesores y alumnos nos conocíamos de espaldas. Después de clases qué interesaba conversar con el profesor o el profesor en clase, qué podía motivarnos para seguir charlando fuera de clases, cosas por el estilo. Con el profesor te veías con más frecuencia cuando estabas haciendo tu tesis, siempre y cuando tuvieras asesor. Incluso nosotros hicimos nuestra tesis sin asesor y lógicamente teníamos problemas para las gestiones burocráticas, dictámenes, etc. Ahora, había personas, como se dice, allegados de la misma orientación política; con ellos conversaban dialogaban, pero ellos no tenían un rol protagónico, dirigencial entre los estudiantes; los estudiantes no iban a hacer eco de lo que decía ese estudiante. Yo pienso que fue una oportunidad excepcional que no se supo aprovechar. Ahora, quien tuvo la mayor responsabilidad por supuesto fue le profesor, porque el profesor debería convocarte en las aulas, decirte "A ver qué temas te interesan", conversar y orientarte, a lo mejor decirte: “¿Sabes qué? Te estás ideologizando demasiado, tú has venido a la universidad a formarte profesionalmente, de ahí que tengas una orientación partidaria, pero estás llegando a este tipo de extremos". Entonces, se polarizó entre estudiantes y profesores. ${ }^{32}$

Las conceptualizaciones sobre el indio en esta etapa estuvieron marcadas por estas divergencias - aunque el indio cedió su lugar a la comunidad campesina como objeto de estudio central- ${ }^{33}$ por lo que encontramos un abanico de

32 Entrevista a Óscar Paredes Pando, 12 de agosto del 2016.

33 Este cambio de perspectiva es importante porque se dejó de lado la categoría "indio", principalmente por el ambiente político que condenaba su uso por la carga discriminatoria que tenía, pero también porque se dejó de hablar del "indio" como sujeto abstracto, debido a lo homogenizante que resultaba, y se dio prioridad a la utilización del concepto de "comunidad campesina" que permitía estudiar las particularidades del objeto de estudio. Por su puesto que esto no significa que anteriormente no se utilizaba el concepto, por el contrario, existen investigaciones que hacían mayor referencia a la comunidad que al indio. Sin embargo, 
estudios con objetivos y perspectivas distintas, debido también a que en esta etapa, la antropología en la UNSAAC no era parte de ningún gran proyecto de investigación y no gozaba de ningún gran financiamiento que centralice la producción académica, como en las dos etapas anteriores. En ese sentido, encontramos un primer grupo de investigaciones donde el indio mantuvo la conceptualización que le había atribuido la antropología aplicada. Estos estudios se caracterizan porque: i) recurren al determinismo geográfico para explicar ii) la situación aislada y cerrada al desarrollo del indio y su comunidad, iii) lo que los mantienen en una situación de casi quietismo cultural, y iv) una situación medrosa y pasiva que requiere ser cambiada mediante su acceso al mercado - . Las tesis para optar el grado de antropólogo de Dunia Marmanillo (1972), Marmanillo, (1972) y Óscar Matutti (1973) son las más representativas de este primer grupo, porque, por ejemplo, Marmanillo, en su tesis titulada tesis C'iyara, una comunidad campesina (1972, p. 63) dice:

C'iyara se ubica en el tipo de comunidad aislada, contando con algunos elementos del tipo de comunidad dependiente. [...] De acuerdo al desarrollo se tipifica como una comunidad estática. [...] Actualmente la comunidad vive en un estado de inercia cultural, tratando de mantener un elevado grado de conservatismo y rechazando la idea de cualquier cambio, sea impuesto o dirigido, que provenga del Gobierno.

Por otro lado, encontramos un grupo de tesis que muestra una preocupación por los fenómenos sociales del contexto y pretenden entenderlos para dar posibles soluciones, donde se observa i) una incursión en temas que anteriormente no eran explorados, por lo que ii) no encuentran una solidez teórica ni en la antropología o la teoría marxista, y iii) se caracterizan por ser más intuitivas al momento de explicar y sustentar sus ideas. Podemos resaltar a los trabajos de Solís (1972) y Miranda (1972), más aun, el último de ellos, porque preocupado por las causas y consecuencias de la migración estudiantil universitaria en la UNSAAC, recurre a las herramientas de la psicología para concluir:

Diremos que el proceso de la inmigración de estudiantes del nivel secundario, a la Universidad Nacional San Antonio Abad del Cusco, trae como consecuencias psíquicas, los desajustes en la formación de la personalidad de los alumnos, el abandono de la universidad por el problema de la inadaptación, a nuevos medios

es en esta nueva etapa que las conceptualizaciones pretenden ser utilizadas con mayor claridad y no con la libertad con la que vimos en los capítulos anteriores. 
i en algunos casos a desequilibrios psíquicos mentales, como consecuencia de estos problemas i los de alimentación (Miranda, 1972, p. 91).

Y finalmente, encontramos un pequeño que se caracteriza por estar cargada i) del discurso marxista de manual, ii) no presentan ninguna - o casi ninguna- investigación de campo, iii) no existe el indio como sujeto, y iv) aunque incluyen algunos conceptos desde la antropología, dan prioridad a conceptos propios del marxismo. El mejor ejemplo de este grupo es la tesis de Efraín Galindo Valdivia (1972) - miembro del partido Patria Roja y cercano a la élite dirigencial一, titulada El Perú en el neocolonialismo, donde concluye:

El neocolonialismo constituye la nueva política fundamental del imperialismo, particularmente yanqui, dirigida a reprimir el Movimiento de Liberación Nacional, i mantener a nuestro país en la órbita del mundo capitalista en su afán de conquistar nuevos mercados i proveerse de materias primas. El imperialismo yanqui bajo su política neocolonial pugna por llegar a ser el gendarme internacional i conquistar la hegemonía mundial (Galindo, 1972, p. 81).

\section{Conclusiones}

A lo largo de este artículo, queda claro que son las condiciones sociales, políticas, culturales e ideológicas de los antropólogos, amalgamadas a las condiciones teóricas e institucionales de la disciplina y hasta cierto punto condicionadas por los diversos contextos regionales, nacionales o internacionales - a los que se enfrentan y con los que dialogan - , las que orientan - y hasta cierto punto definen - la forma de producción de conocimiento antropológico y la forma de construcción de institucionalidad de una comunidad académica. La capacidad de agencia de los antropólogos para desenvolverse en estos distintos escenarios completa el esquema, pues son estos elementos los que nos permiten entender por qué la antropología en el Cusco se desarrolló de tal forma que perdió tan tempranamente el protagonismo institucional en el país - y con ello los financiamientos y las redes académicas - frente a otras instituciones antropológicas como la UNMSM o el IEP, o por qué fracasó el intento de construir una antropología marxista en el Cusco. Estudiar estos procesos de gestación de conocimiento resulta importante para entender cómo hemos llegado hasta aquí y qué horizontes estamos construyendo para nuestra disciplina. Además, nos permite entender a la antropología desde la diversidad en 
la que vivimos, pues pese a que las experiencias regionales estén atravesadas por contextos generales, son sus particularidades las que marcan el desarrollo particular de la disciplina y con ella, la forma de conceptualizar al objeto de estudio y entender la realidad.

En ese sentido, considero que la teoría que se aprendió en la Escuela de Antropología de la UNSAAC - imposibilitada para entender conceptualmente el conflicto-, la condición social y política de la mayoría de los antropólogos — marcados por el conservadurismo social de la sociedad cusqueña-, así como la relación que tuvieron con el contexto ideológico en el que se desenvolvieron - caracterizado por la incapacidad de trasladar la perspectiva crítica del ambiente político al ambiente académico—- solo podía conducir al surgimiento y desarrollo de una antropología conservadora en el Cusco, pese a que existieron intentos disidentes - y finalmente fallidos - por construir antropologías distintas. La forma cómo se estudió y conceptualizó al indio tuvo como característica la vena conservadora — donde primaba la aproximación tutelar del investigador a su objeto de estudio-, y el halo de los indigenismos, que al mismo tiempo de esencializar al indio y su cultura, lo condenaban a su inevitable inclusión a la vida nacional vía la desindianización.

¿Continuó esta perspectiva en los años siguientes a nuestra investigación? Considero que aún queda mucho por estudiar para entender qué pasó con la antropología y cómo conceptualizó a su objeto de estudio, por ejemplo, en pleno conflicto armado interno, en el boom de las ONG, en la acogida de las consultorías o en un contexto neoliberal como en el que vivimos. Sin embargo, me atrevo a decir que la antropología en el Cusco, hasta ahora, no ha logrado replantearse y mantiene los derroteros que describimos en este artículo. Tal vez por eso sigue siendo tan lejana a los problemas de la actualidad y no logra establecer, por ejemplo, espacios — cursos en pregrado, maestría, talleres, diplomados, etc. - para entender las problemáticas que genera el turismo como la precariedad laboral, explotación sexual, etc. — siendo el Cusco el principal destino turístico del país-, u observatorios sobre conflictos sociales o el impacto de la minería - siendo el Cusco una de las regiones con mayor presencia minera y con mayor índice de conflictos sociales del país. 


\section{Bibliografía}

Achachau Huatuco, R. (1970). Algunos aspectos de la organización social de Acolla [tesis de licenciatura]. Cusco: Universidad Nacional San Antonio de Abad del Cusco. Adrián, J. M. y Cáceres, C. (1970). Los sikho morenos de Llavini [tesis de licenciatura]. Cusco: Universidad Nacional San Antonio de Abad del Cusco.

Aparicio Vega, M. J. (2012). Centenario de la generación La Sierra. Lima: Asamblea Nacional de Rectores.

Aramburú, C. (1978). Aspectos del desarrollo de la Antropología en el Perú. En B. Podestá (Ed.). Ciencias sociales en el Perú: un balance crítico. Lima: CIUP.

Calvo, R. (2010). La antropología urbana en el Cusco. Antrophosentido, I, 103-118.

Castro, M. (2014). A setenta años de la antropología en Chile. Antropologías del Sur, 43-64.

Cortéz, L. (2015). Entre la antropología activista y el análisis sociopolítico. La antropología y el proceso de desarrollo en la Amazonía peruana (1983-2015). Estructura Salvaje, 4, 37-60.

Cuadros, F. (1990). La vertiente cusqueña del comunismo peruano. Lima: Editorial Horizonte.

De la Cadena, M. (2004). Indígenas mestizos. Raza y cultura en el Cusco. Lima: Instituto de Estudios Peruanos.

De la Cadena, M. (1997). La decencia y el respeto. Raza y etnicidad entre los intelectuales y las mestizas cusqueñas. Lima: Instituto de Estudios Peruanos.

Degregori, C. I. (2014). ¿Cómo despertar a la bella durmiente? Por una antropología para el Perú. Lima: Instituto de Estudios Peruanos.

Degregori, C. I. (2008). ¿Cómo despertar a la bella durmiente?: por una antropología para comprender un país escindido. En La antropología ante el Perú de hoy. Balances regionales y antropologías Latinoamericanas. Lima: CISEPA, Fondo Editorial de la Pontificia Universidad Católica del Perú.

Degregori, C. I. (2000a). Panorama de la antropología en el Perú: del estudio del otro a la construcción de un nosotros diverso. En C. I. Degregori (Ed.). No hay país más diverso. Compendio de antropología peruana (pp. 20-74). Lima: Instituto de Estudios Peruanos.

Degregori, C. I. (Ed.) (2000b). No hay país más diverso. Compendio de antropología peruana. Lima: Instituto de Estudios Peruanos.

Degregori, C. I. Sandoval, P. (2019). Antropología y antropólogos en el Perú. La academia de ciencias sociales bajo la modernización neoliberal. Lima: Instituto de Estudios Peruanos. 
Degregori, C. I. y Sandoval, P. (Eds.) (2007). Saberes periféricos. Lima: Instituto de Estudios Peruanos.

Degregori, C. I., Sandoval, P. y Sendon, P. (Eds.). (2012). No hay país más diverso. Compendio de antropología peruana (vol. II). Lima: Instituto de Estudios Peruanos.

Destua, J. y Rénique, J. L. (1984). Intelectual, intelectuales y descentralismo en el Perú 1897-1931. Cusco: Centro Bartolomé de las Casas.

Diez, A. (Ed.). (2008). La antropología ante el Perú de hoy. Balances regionales y antropologías Latinoamericanas. Lima: CISEPA, Fondo Editorial de la Pontificia Universidad Católica del Perú.

Dirección Nacional de Estadística y Censos (1961). Primer censo nacional agropecuario. Lima: Instituto Nacional de Planificación.

El Comercio (19 de enero de 1942). Cusco. El Comercio.

El Sol del Cusco (9 de setiembre de 1972). Cusco. El Sol del Cusco.

Flores Ochoa, J. (2013). Axel Wenner-Gren y la antropología cuzqueña. En C. D. Cuzco, Anales de tinkuy. Encuentro con la cultura andina (pp. 12-22). Cusco: Centro de Estudios Andinos Cuzco.

Flores Ochoa, J., Nuñez del Prado, Bejar, J. y Castillo Farfán, M. (2005). Q'ero, el último ayllu inca. Homenaje a Óscar Núñez del Prado y la expedición de la UNSAAC a la nación Q ero en 1955. Cusco: Instituto Nacional de Cultura.

Franco, C. (1987). Los significados de la experiencia velasquista: forma política y contenido social. En C. Franco (Cord.) El Perú de Velasco (vol. II). Lima: CEDEP.

Fuentes, E. (1969). La cultura tradicional y los cambios en la comunidad de Matinga [tesis de licenciatura]. Cusco: Universidad Nacional San Antonio de Abad del Cusco. Fuentes, G. (1947). Algunos aspectos antropológicos del distrito de Chinchero [tesis de licenciatura]. Cusco: Universidad Nacional San Antonio de Abad del Cusco.

Gonzales, C. y Roca, R. (2010). Antropología en el Cusco. Breve referencia. El Antoniano, $115,15-23$.

Gutiérrez, J. (1988). Así nació el Cusco rojo. Contribuciones a su histórica polítca: 19241934. Lima.

Gutiérrez, R., Pernault, C., Viñuales, G., Escobari, L., Querejazu, P., Rodríguez, H., ..., Lambarri, J. (1984). Notas sobre las haciendas del Cusco. Buenos Aires: Fundación para la Educación, la Ciencia y la Cultura.

Lynch, N. (1979). La polémica indigenista y los orígenes del comunismo en el Cusco. Crítica Andina, 5-46.

Marmanillo, D. (1972). C'iyara, una comunidad campesina [tesis de licenciatura]. Cusco: Universidad Nacional San Antonio de Abad del Cusco. 
Matutti, O. (1973). La antropología y el desarrollo comunal. Educación formal en 18 comunidades campesinas colindantes con el lago Titikaka-Puno [tesis de licenciatura]. Cusco: Universidad Nacional San Antonio de Abad del Cusco.

Miranda, E. (1972). Migración estudiantil universitaria en la ciudad del Cusco. Causas y consecuencias [tesis de licenciatura]. Cusco: Universidad Nacional San Antonio de Abad del Cusco.

Montoya, R. (1975). Colonialismo y antropología en Perú. Nueva Antropología, 2.

Montoya, R. (2018). Desde el sur: los otros como parte de nosotros, pensamiento crítico en las antropologías. Discursos del Sur, 1, 101-128.

Núñez del Prado, J. V. (1970). El mundo sobrenatural de los quechuas del sur del Perú a través de la comunidad de Qotobamba [tesis de licenciatura]. Cusco: Universidad Nacional San Antonio de Abad del Cusco.

Núñez del Prado, O. (1970). Un ensayo de integración de la población campesina. El caso de Kuyo Chico (Cusco). Lima: Instituto de Estudios Peruanos.

Núñez Mendívil, M. (1970). Urinsaya Qollana [tesis de licenciatura]. Cusco: Universidad Nacional San Antonio de Abad del Cusco.

Paredes, O. (2009). Crónicas de la primera reforma universitaria del Perú y auroral de América del sur. Cusco 1907-1909. Cusco: Municipalidad del Cusco.

Paredes, O. (2015). La UNSAAC nació con las ciencias humanas y sociales. Cusco: Universidad San Antonio Abad del Cusco.

Pajuelo, R. (2000a). Imágenes de la comundiad. Indígenas, campesinos y antropólogos en el Perú. En C. I. Degregori (Ed.). No hay país más diverso. Compendio de antropología peruana (pp. 123-179). Lima: Instituto de Estudios Peruanos.

Pastor, H. R. (1985). La antropología en el Perú. Lima: CONCYTEC.

Rénique, J. L. (1991). Los sueños de la sierra. Cusco en el siglo xx. Lima: Centro Peruano de Estudios Sociales.

Sandoval, P. (2012). Antropología y antropólogos en el Perú: discursos y prácticas en la representación del indio, 1940-1990. En P. Sandoval y P. Sendón (Eds.). No hay país más diverso. Compendio de antropología peruana (vol. II). Lima: Instituto de Estudios Peruanos.

Solís, E. (1972). Gobierno y autoridad en la comunidad de Makay (Qoya-Calca-Cusco) [tesis de licenciatura]. Cusco: Universidad Nacional San Antonio de Abad del Cusco.

Urrutia, J. (1992). Comunidades campesinas y antropología: historia de un amor (casi) eterno. Debate Agrario, 14, 1-16.

Valderrama, R. y Escalante, C. (2010). La etnografía andina. Antrophosentido, I, 23-45. 